\title{
Análisis del impacto en fumadores mexicanos de los avisos gráficos en las cajetillas de cigarros
}

\author{
James Francis Thrasher, M en C, PhD, ${ }^{1,2}$ Betania Allen, M en Antrop, ${ }^{(3)}$ Luz Myriam Reynales-Shigematsu, Dr en C, ${ }^{(1)}$
} Rafael Anaya, M en C, ${ }^{(3)}$ Eduardo Lazcano-Ponce, Dr en C, ${ }^{(4)}$ Mauricio Hernández-Avila, Dr en C. ${ }^{(5)}$

\begin{abstract}
Thrasher JF, Allen B, Reynales-Shigematsu LM Anaya R, Lazcano-Ponce E, Hernández-Avila M. Análisis del impacto en fumadores mexicanos de los avisos gráficos en las cajetillas de cigarros. Salud Publica Mex 2006;48 supl I:S65-S74.
\end{abstract}

\section{Resumen}

Objetivo. Determinar el impacto de los avisos gráficos (imágenes en las etiquetas que indican el daño a la salud que causa el tabaco) en las cajetillas de cigarros entre fumadores adultos mexicanos. Material y métodos. Se aplicó el método antropológico de sorteo de montones a 60 fumadores adultos para determinar cuáles los hacían pensar en dejar de fumar. Se sacaron promedios y se utilizaron métodos estadísticos no paramétricos. Resultados. Los avisos gráficos más impactantes mostraban las siguientes imágenes: un tumor de bronquio fuente visto a través del broncoscopio; un hombre con cáncer de laringe con una gran masa tumoral externa en el cuello; un hombre joven inconsciente en una cama de la unidad de cuidados intensivos, con texto mencionando benceno, formaldehído y cianuro de hidrógeno como componentes del tabaco,y una de dos niños sanos que indica que el cigarro contiene amoníaco, monóxido de carbono; un feto muerto en un frasco con formol; $y$ una boca con dientes amarillos y con texto que menciona la pérdida de dientes y cáncer bucal como resultados del tabaco. Conclusiones. Los avisos gráficos que se utilizan en las cajetillas de cigarros en otros países podrían contribuir a la cesación entre fumadores mexicanos y deben implementarse en México.

Palabras clave: avisos gráficos en las cajetillas; sorteo de montones; tabaco; México
Thrasher JF, Allen B, Reynales-Shigematsu LM,

Anaya R, Lazcano-Ponce E, Hernández-Avila M. Analysis of the impact of cigarette pack graphic warnings on Mexican smokers.

Salud Publica Mex 2006;48 suppl I:S65-S74.

\section{Abstract}

Objective. To determine which graphic warnings on cigarette packs (images on the labels indicating the negative impact on health that tobacco can have) provoke the strongest desire to quit smoking among adult Mexican smokers. Material and Methods. A pile sort method was used among 60 smokers over 18 years old to determine which images made them think about quitting smoking. Averages were determined and non-parametric statistical methods were used to determine differences in ranks. Results. Within each of the five themes, one or two graphic warnings provoked the strongest responses in smokers. The graphic warnings with the greatest impact used the following images: a close-up of a lung tumor; a man with cancer of the larynx with a large tumorous mass on the exterior part of his neck; an unconscious young man in a bed in an intensive care unit with text mentioning benzene, formaldehyde and cyanide as tobacco components; an image of two healthy children indicating that cigarettes contain carbon monoxide; an image of a dead fetus in a specimen jar; and a close up of a mouth with yellow, rotting teeth and text describing tooth loss and mouth cancer as a result of tobacco use. Conclusions. The graphic warnings used on cigarette packs in other countries could contribute to cessation among Mexican smokers and should be implemented in Mexico.

Key words: graphic warning labels; pile sort; tobacco; Mexico

(I) Departamento de Investigación sobre tabaco. Centro de Investigación en Salud Poblacional, Instituto Nacional de Salud Pública (INSP), Cuernavaca, Morelos, México.

(2) Instituto de Investigación en Políticas y Salud, Universidad de Illinois, Chicago, EUA

(3) Subdirección de Salud Reproductiva, Centro de Investigación en Salud Poblacional, INSP, Cuernavaca, Morelos, México.

(4) Dirección Adjunta, Centro de Investigación en Salud Poblacional, INSP, Cuernavaca, Morelos, México.

(5) Dirección General, INSP, Cuernavaca, Morelos, México.

Fecha de recibido: 8 de marzo de 2006 - Fecha de aprobado: 24 de abril de 2006 Solicitud de sobretiros: James Francis Thrasher. Instituto Nacional de Salud Pública. Av. Universidad 655. Sta. Ma. Ahuacatitlán, 62508 Cuernavaca, Morelos, México. Correo electrónico: jfthrasher@insp.mx 
E consumo de tabaco es la principal causa evitable de mortalidad prematura en el mundo. ${ }^{1-3}$ Una estrategia de control del tabaquismo utilizada para desalentar y promover la cesación del consumo de tabaco es el uso de los avisos gráficos (pictogramas o imágenes) en las cajetillas de cigarros, los cuales tienen como objetivo principal informar a los fumadores acerca de los daños a la salud y las consecuencias que ocasiona el consumo de tabaco. ${ }^{4}$ Actualmente, la evidencia científica sugiere que las etiquetas que informan acerca de los daños a la salud por consumo de tabaco que además incluyen imágenes gráficas -usualmente fotografías- son más efectivas e impactantes que las etiquetas que incluyen únicamente texto. ${ }^{5}$ Por ejemplo, en un momento en el cual Canadá era el único país con avisos gráficos en sus cajetillas se realizó un estudio entre fumadores de este país, Australia, Inglaterra y Estados Unidos, y resultó ser más probable que los canadienses vieran las etiquetas a que las leyeran o examinaran detalladamente, y que reportaran que las etiquetas los habían motivado a dejar de fumar un cigarro. * Además, las imágenes que comunican las consecuencias del consumo de tabaco podrían ser más eficaces entre la población analfabeta, ya que evidentemente este grupo no lee los mensajes que se expresan únicamente a través del texto. Las etiquetas con imágenes llaman la atención de los fumadores, desalientan el consumo de cigarros y promueven el abandono del hábito de fumar. ${ }^{6}$

Según las teorías de la comunicación para promover la salud ${ }^{7,8}$ las etiquetas que aparecen en los paquetes de cigarros son ideales para la transmisión de mensajes sobre los efectos nocivos del consumo de tabaco. Las razones de ello son las siguientes: a) tales mensajes alcanzan al público deseado: los fumadores y los que están interesados en fumar; b) el momento en que se transmiten los mensajes a los fumadores es óptimo, ya que el mensaje les llega cuando compran y luego cuando fuman los cigarros; c) los fumadores se exponen a los mensajes con cierta regularidad; por ejemplo, una persona que fuma una cajetilla diaria podría estar expuesta a los avisos 20 veces al día o 7300 veces al año; d) se pueden variar los mensajes que aparecen en las cajetillas para evitar el desgaste de los avisos, lo que implica la pérdida del impacto del mensaje cuando el fumador se acostumbra a leerlo; ${ }^{9}$ y e) la implementación de políticas al respecto puede obligar a la industria

\footnotetext{
* Hammond D, Fong GT, McNeil A, Borland R, Cummings KM. The effectiveness of cigarette warning labels in informing smokers about the risks of smoking. Tobacco Control. En prensa.
}

tabacalera a pagar los costos de imprimir los avisos que aparecen en la etiqueta de las cajetillas de cigarro, lo que hace que esta estrategia de comunicación sea más costo-efectiva que otros esfuerzos, como por ejemplo los anuncios trasmitidos por los medios masivos.

Este artículo describe los resultados y algunas implicaciones metodológicas de un estudio exploratorio cuyo objetivo principal es determinar el efecto de los avisos gráficos en el deseo de dejar de fumar entre fumadores adultos mexicanos.

\section{Material y métodos}

Se seleccionaron 60 fumadores mayores de 18 años de edad de la ciudad de Cuernavaca, Morelos, que reportaron haber fumado más de 100 cigarros en su vida y al menos uno en el último mes. Se tomaron las imágenes y los textos de avisos gráficos de Canadá, Brasil y la Comunidad Económica Europea, ${ }^{10-12}$ los cuales fueron traducidos al español e impresos sobre una tarjeta del tamaño de una cajetilla de cigarros genéricos (es decir, $6 \mathrm{~cm}$ por $9.3 \mathrm{~cm}$ ). En la parte inferior de las tarjetas se ubicaron los avisos gráficos y los textos, en la parte superior se colocaron las palabras "Marca" y "cigarros" evitando colocar nombres o marcas comerciales. Los avisos gráficos se clasificaron en cinco categorías temáticas: a) cáncer del pulmón $(\mathrm{n}=6)$; b) otros daños mortales a largo plazo (n=9); c) contenido del tabaco $(n=6) ; d)$ enfermedades crónicas y daños a corto plazo $(n=10) ; y$ e) daños a la salud en las mujeres embarazadas y en los niños $(n=10)$ (anexo 1.)

Previo consentimiento verbal, a cada participante se le realizó una encuesta breve indagando acerca de los datos sociodemográficos (edad, género, nivel educativo), y el consumo de tabaco (marca de cigarrillos usual, cantidad y frecuencia de fumar, número de intentos de dejar de fumar). Posteriormente, se aplicó el método de sorteo de montones, también llamado clasificación de ideas. ${ }^{13-15}$ Este método se ha utilizado con anterioridad para investigar acerca de las percepciones, las similitudes culturales y la variación intracultural. ${ }^{16,17}$ Se entregó a cada participante un grupo (o "montón") de tarjetas con los avisos gráficos que correspondían a una de las cinco categorías temáticas previamente establecidas. Se le pidió que ordenara las tarjetas en orden descendente de mayor a menor impacto, explicándole que una tarjeta "impactante" era aquella que le hiciera pensar en dejar de fumar. Estas instrucciones se repitieron para cada una de las cuatro categorías restantes. Al final, se le pidió a cada participante que escogiera los tres avisos gráficos más impactantes y que comentara por qué le había dado prioridad a la imagen que consideró más impactante que ningu- 
na otra. Los comentarios se anotaron textualmente, luego se clasificaron según las cinco categorías predeterminadas y, por último, se leyeron y se agruparon otra vez según los temas que surgían de los mismos comentarios.

Para el análisis estadístico cuantitativo se dio un valor a cada imagen que correspondió al lugar en el rango de más a menos impactante que le asignó cada participante. Por ejemplo, para el aviso seleccionado como más impactante dentro de la categoría de "cáncer del pulmón" se asignó un valor de seis porque hay seis tarjetas dentro de esa categoría. Se asignó un valor de cinco al aviso seleccionado como el segundo más impactante, etc. El valor que correspondió al lugar en el rango dependió del número de avisos evaluados dentro de la categoría. Se estimaron los promedios para cada aviso gráfico en toda la muestra; y la muestra se estratificó según las características sociodemográficas y de consumo de tabaco con el objeto de conocer las posibles variaciones en los resultados. A su vez, para analizar las diferencias entre los rangos dados a los avisos gráficos, se aplicó la prueba de suma de rangos de Wilcoxon, que es el equivalente no paramétrico de la prueba $t$ para muestras pareadas. ${ }^{18}$ Esta prueba permitió comparar los rangos dados al aviso con el promedio más alto dentro de la categoría de interés, con lo que se indica cuál era el aviso más impactante. La prueba de Kruskall-Wallis es el equivalente no paramétrico del análisis de varianza (ANOVA) y se utilizó para estimar las diferencias entre los rangos para el aviso con promedio más alto dentro de las categorías de una submuestra (hombre vs. mujer). Por tener una muestra pequeña, se fijó el valor de significancia de $p$ de 0.10 en todas pruebas. El análisis se realizó utilizando el paquete estadístico STATA v8.0.

\section{Resultados}

La muestra del estudio se compone de 31 mujeres y 29 hombres con una edad promedio de 40 años (rango 18 a 68 años), con $12 \%$ ( $n=7)$ con nivel de escolaridad primaria, $25 \%(n=15)$ secundaria, $18 \%(n=11)$ preparatoria, $10 \%(n=6)$ escuela técnica, $23 \%(n=14)$ licenciatura, y $5 \%(n=3)$ posgrado. En cuanto al consumo de tabaco, $62 \%(n=37)$ de los participantes consume menos de seis cigarros al día, la mitad ( $\mathrm{n}=30)$ de los fumadores nunca había intentado dejar de fumar, una cuarta parte $(n=15)$ había intentado dejarlo en los últimos seis meses, y la otra cuarta parte $(n=13)$ lo había hecho más de seis meses antes del momento de la entrevista.

La figura 1 presenta los promedios dados a cada imagen dentro de cada categoría, a nivel de toda la po- blación de estudio. El máximo valor del promedio depende del número de avisos en la categoría de interés; por ejemplo, el máximo fue de seis para los avisos gráficos en la categoría "cáncer del pulmón", ya que había seis imágenes en esta categoría. El cuadro I presenta los avisos gráficos considerados como los más impactantes a nivel de toda la población de estudio y en cada una de las categorías establecidas. El orden de las imágenes está determinado por el promedio del impacto dado a cada aviso gráfico, mientras que el promedio más alto se presenta al lado izquierdo y el más bajo a la derecha. En las celdas donde se observa más de un dato significa que no hay diferencia estadísticamente significativa entre el promedio más alto y los demás incluidos en la misma celda (prueba de suma de rangos de Wilcoxon $p^{*} 0.10$ ). De igual manera, cuando sólo aparece un dato dentro de la celda, significa que la prueba estadística tuvo la capacidad de discriminar el aviso más impactante, lo que indica que el resultado es estadísticamente significativo. (prueba de suma de rangos de Wilcoxon $p$ ) 0.10)

Avisos referentes al cáncer de pulmón. En esta categoría el aviso gráfico que obtuvo el promedio más alto fue el que mostró un tumor de bronquio fuente visto a través del broncoscopio creciendo dentro de un pulmón (P1); sin embargo, la prueba estadística de suma de rangos de Wilcoxon no fue capaz de discriminar entre los rangos de este aviso y otro que muestra una pieza patológica en bloque de dos pulmones con cáncer (P0). Cuando se realizó este mismo análisis por género, edad, nivel educativo (primaria y secundaria) y consumo de tabaco, el aviso gráfico P1 obtuvo el promedio más alto y fue el segundo mayor en los dos grupos restantes. (Figura 2a). Los resultados de la prueba de KruskallWallis sugieren que el P0 fue más impactante en los fumadores que nunca habían intentado dejar de fumar en comparación con los que lo habían hecho.

Cuando los fumadores seleccionaban las imágenes relacionadas con el cáncer de pulmón comentaban su preocupación por los órganos en general ("por como quedan los órganos", "nunca había visto órganos así") y por los pulmones en específico ("por como quedan los pulmones cuando se fuma demasiado", "porque se refiere al pulmón, entonces es más probable que un fumador asiduo contraiga [cáncer] de pulmón"). Algunos participantes vincularon las imágenes o el texto a la adicción al tabaco o al uso prolongado de esta sustancia ("uno está así, hasta el último, y no deja de fumar; me podría pasar eso si no dejo de fumar", "a veces por necio fuma uno y al final se daña [a] uno mismo y a terceras personas"). 


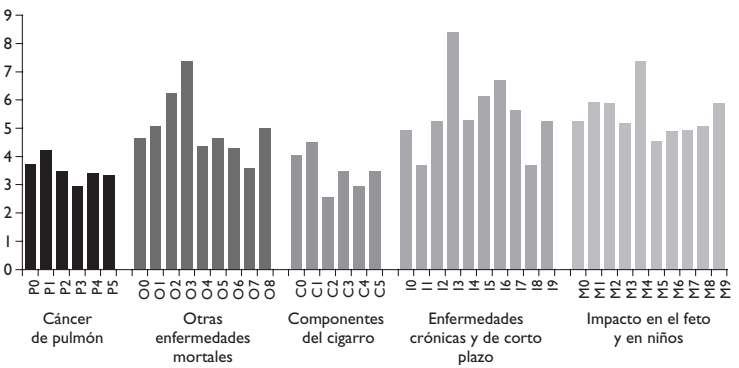

Figura I. Promedios del lugar en el rango de más a MENOS IMPACTANTE QUE LOS FUMADORES ASIGNARON A Cada imagen por categoría, Cuernavaca, Morelos, MÉxICO, 2005.
Avisos referentes a otros daños mortales a largo plazo. En esta categoría los fumadores identificaron claramente dos avisos gráficos como los más impactantes: el aviso O3, que muestra un hombre con cáncer de laringe y una gran masa tumoral externa en el cuello (figura $2 b$ ); y el aviso $\mathrm{O} 2$, que muestra una pieza de patología de un cerebro con trombosis cerebral. El aviso gráfico O3 presentó el promedio más alto a nivel general y en todos los estratos por edad, género, nivel educativo y consumo de tabaco. De igual manera el aviso $\mathrm{O} 2$ presentó el segundo promedio más alto en seis categorías aunque los resultados no fueron estadísticamente significativos. Finalmente, es importante mencionar que el aviso $\mathrm{O} 3$ fue el más impactante entre los fumadores que habían intentado dejar de fumar, aunque la prue-

Cuadro I

Avisos gráficos de mayor IMPACto en fumAdores Adultos. MÉXico 2005

Características de la muestra

\begin{tabular}{ccccc}
\hline \multirow{3}{*}{ Cáncer de pulmón } & Categoría temática & & \\
& Otros daños & Componentes & Enfermedades & Impacto en las \\
& del cigarro & crónicas y daños & mujeres embarazadas \\
& & a corto plazo & y en los niños
\end{tabular}

Toda la muestra

PI,PO*

$\mathrm{O3}$

$\mathrm{Cl}, \mathrm{CO}$

13

M4

Género

\begin{tabular}{lcccccc} 
Hombres & $\mathrm{PI}, \mathrm{P} 4$ & $\mathrm{O3,O} 2$ & $\mathrm{Cl}$ & $\mathrm{I3}$ & $\mathrm{M4}, \mathrm{M3}$ \\
\hline Mujeres & $\mathrm{PI}, \mathrm{PO}, \mathrm{P} 4$ & $\mathrm{O} 3$ & $\mathrm{C} 0^{\ddagger}, \mathrm{Cl}$ & $\mathrm{I3}$ & $\mathrm{M4,MI}$
\end{tabular}

Edad

\begin{tabular}{|c|c|c|c|c|c|}
\hline$<40$ años & $\mathrm{PI}, \mathrm{P} 0, \mathrm{P} 3$ & $\mathrm{O} 3, \mathrm{O} 2$ & $\mathrm{Cl}, \mathrm{CO}$ & 13 & $M 4 \S$ \\
\hline más de 40 años & $\mathrm{PI}, \mathrm{P} 0, \mathrm{P} 4$ & $\mathrm{O} 3$ & $\mathrm{Cl}, \mathrm{C} 0, \mathrm{C} 5$ & 13,16 & M4,M0,M9,MI,M8,M2,M3,M7 \\
\hline
\end{tabular}

Nivel educativo

\begin{tabular}{|c|c|c|c|c|c|}
\hline Primaria / secundaria & $\mathrm{PI}, \mathrm{P} 4, \mathrm{P} 5, \mathrm{P} 2$ & $\mathrm{O} 3, \mathrm{O} 2$ & $\mathrm{Cl}, \mathrm{CO}$ & $13,16,10$ & M4,MI,M3,M2,M9,M5,M7 \\
\hline Preparatoria / técnica & $\mathrm{PI}, \mathrm{P0}, \mathrm{P3}$ & $\mathrm{O} 3, \mathrm{O} 2$ & $\mathrm{Cl}, \mathrm{C} 0, \mathrm{C} 5$ & 13,16 & M4 \\
\hline Licenciatura / posgrado & P0ई,PI,P2, P4,P5 & $\mathrm{O3}$ & $\mathrm{C} 0, \mathrm{Cl}, \mathrm{C} 5$ & 13 & M4,M9 \\
\hline
\end{tabular}

Número de cigarros

\begin{tabular}{lcccccc}
$<6 /$ día & $\mathrm{PI}, \mathrm{P} 0, \mathrm{P} 4, \mathrm{P} 5$ & $\mathrm{O} 3, \mathrm{O} 2$ & $\mathrm{Cl}, \mathrm{C} 0$ & $\mathrm{I3}$ & $\mathrm{M4}$ \\
\hline más de 6/día & $\mathrm{PI}, \mathrm{P} 0, \mathrm{P} 2$ & $\mathrm{O} 3$ & $\mathrm{Cl}, \mathrm{C} 5, \mathrm{C} 0$ & $\mathrm{I3}, \mathrm{l6}$ & $\mathrm{M} 4, \mathrm{M} 2, \mathrm{MIM}, \mathrm{M0}, \mathrm{M3}$
\end{tabular}

Dejar de fumar

\begin{tabular}{|c|c|c|c|c|c|}
\hline Nunca & $\mathrm{P} 0^{\ddagger}, \mathrm{PI}$ & $\mathrm{O} 3, \mathrm{O} 2$ & $\mathrm{Cl}, \mathrm{CO}$ & 13 & M4 \\
\hline Alguna vez & $\left.\mathrm{P}\right|^{\S}$ & $\mathrm{O}^{\S}$ & $\mathrm{Cl}, \mathrm{C} 0, \mathrm{C} 3, \mathrm{C} 5$ & 13 & M4, M9, M8, M2, M3 \\
\hline
\end{tabular}

* Los símbolos $\mathrm{PI}, \mathrm{PO}, \mathrm{O} 3, \mathrm{Cl}$, etc., representan los avisos gráficos. El anexo I describe todas las imágenes y la figura I muestra los promedios para cada imagen en toda la población del estudio. En este cuadro sólo se presentan los símbolos que corresponden a los avisos gráficos que tuvieron el mayor impacto. En las celdas donde aparece más de un símbolo, significa que no hay diferencia entre la distribución de lugares dentro del rango de impacto del aviso, con el promedio más alto y los demás avisos incluidos en la misma celda (i.e., prueba de suma de Rangos de Wilcoxon $p>=0$. I0). En estos casos, el aviso con el promedio más alto aparece al lado izquierdo

‡ Al valor de $p<0$. I0, la prueba de Kruskall-Wallis indica que el impacto del aviso indicado es mayor que el grupo de comparación

$\S$ En el caso de un valor de $p<0.05$, la prueba de Kruskall-Wallis indica que el impacto del aviso indicado es mayor que el grupo de comparación 


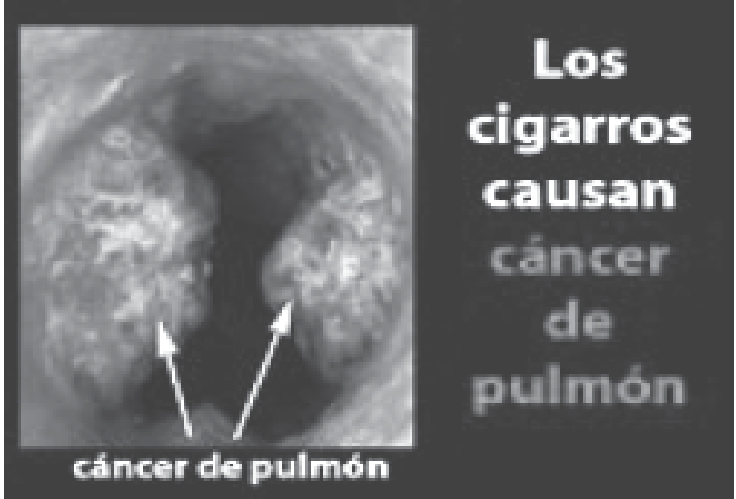

a. Aviso PI

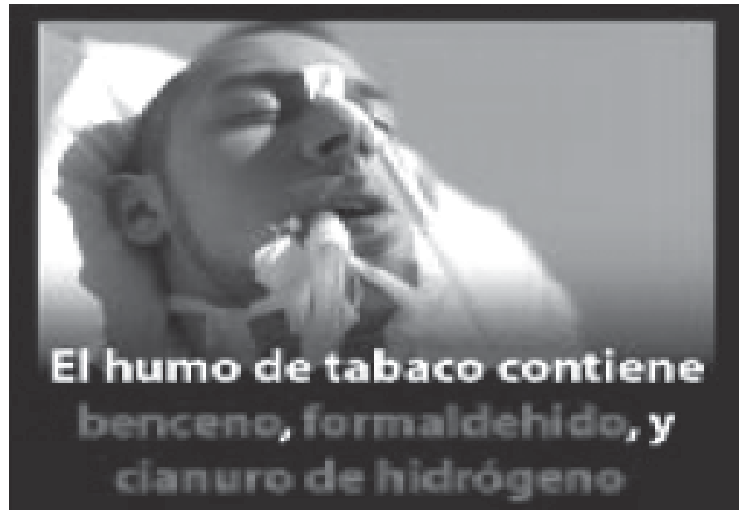

c. Aviso $\mathrm{Cl}$

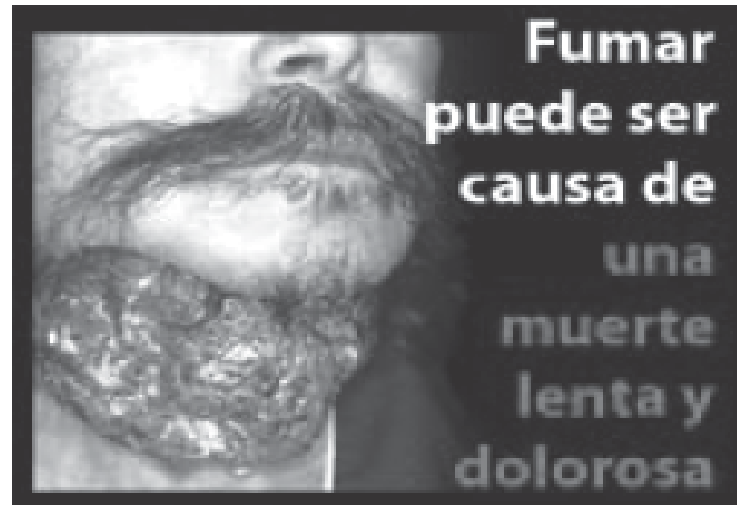

b. Aviso $\mathrm{O} 3$

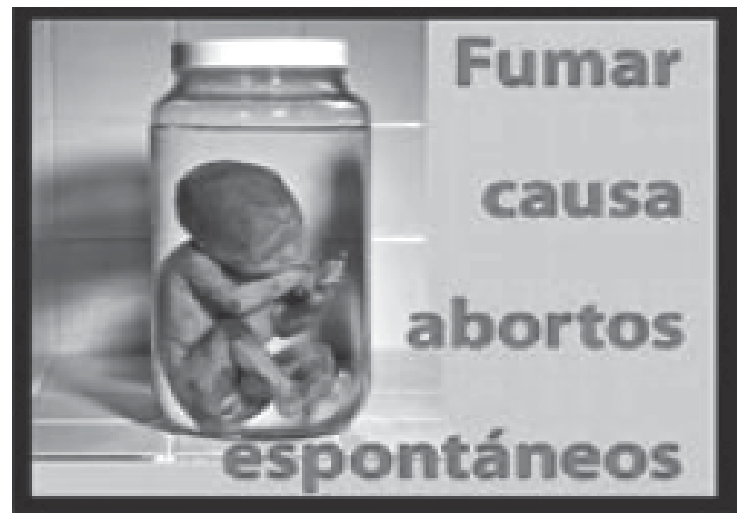

d.Aviso M4

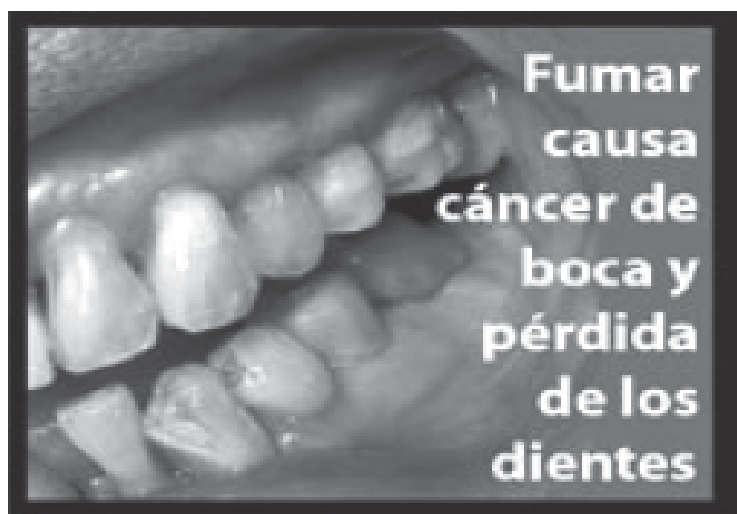

e. Aviso 13

Figura 2. Los avisos gráficos más impactantes para una población de fumadores mexicanos adultos. CuernavacA, Morelos, México, 2005. 
ba de Kruskall-Wallis indicó que este aviso tenía más impacto en los que habían intentado dejar de fumar alguna vez en relación con los que lo habían intentado hacía menos de seis meses.

Los comentarios textuales sobre el aviso O3 solían enfatizar lo aparente o visible del tumor: "se ve por fuera, salido", "lo estás viendo fuera, de adentro del pulmón no se ve, aquí se ve el daño", "se ve una bola en la garganta", "por lo que se observa, cómo se hace la garganta" y "por lo que se ve en el exterior". Al ser perceptible a simple vista, parece ser que hay una mayor credibilidad de la posibilidad de que fumar tabaco causa un tumor. Al tratarse de un tumor que cualquier persona puede percibir, y no algo que requiere un diagnóstico especializado o una técnica médica para demostrarlo, parece tener una mayor validez y un mayor impacto en algunos fumadores. Por otra parte, tal vez por ser visible, por el color rojo o por alguna otra característica de la fotografía, muchos fumadores vinculaban la imagen con el dolor o el sufrimiento: "el dolor, qué dolor tener un cáncer así, ha de ser doloroso, pensar en el dolor que puedes sentir", "los padecimientos que se sufren", "el daño que tiene".

Avisos referentes a los componentes del cigarro. Los fumadores señalaron dos imágenes como las más impactantes: el aviso $\mathrm{C} 1$, que presenta un hombre joven inconsciente en una cama de la unidad de cuidados intensivos, con el texto "El humo de tabaco contiene benceno, formaldehído y cianuro de hidrógeno" (figura 2c); y el aviso $\mathrm{C} 0$, que muestra dos niños sanos con el texto "El humo del cigarro que inhalan los no fumadores contiene amoníaco, monóxido de carbono, que pueden perjudicar a sus hijos". Cuando se realizó el análisis por género el aviso gráfico $\mathrm{C} 1$ obtuvo el promedio más alto en los hombres y no se pudo distinguir el aviso C0 y el C1 en mujeres. Aunque la prueba de KruskallWallis reveló que las mujeres dieron un rango más alto que los hombres al aviso $\mathrm{C} 0$, en los otros grupos no fue posible discriminar entre el aviso gráfico C0 y C1. En varios estratos el aviso gráfico $\mathrm{C} 5$, que muestra una rata y cucaracha muertas y con el texto "Al fumar inhala arsénico y naftalina, también usados contra ratas y cucarachas" no fue posible discriminarlo con el aviso $\mathrm{C} 1$ y el $\mathrm{C} 0$ como el más impactante. Al respecto de esta imagen, un participante dijo que "todas [las imágenes] son relevantes, la información sobre el contenido [del tabaco] es más importante".

Avisos gráficos referentes a los daños a las mujeres embarazadas y en los niños. El M4, que presenta una fotografía de un feto muerto en un frasco con formol y con el texto "Fumar causa abortos espontáneos", fue el más impactante de esta categoría (figura 2d). Este resultado se dio de igual manera en los menores de 40 años, aquellos con educación media y técnica y en aquellos que nunca han intentado dejar de fumar. El aviso M4 alcanzó promedio más alto en todos grupos, pero en algunas poblaciones no se pudo distinguir del nivel de impacto alcanzado por varias otras imágenes dentro de esta categoría.

En general para todas las imágenes de esta categoría, fue la preocupación por el hecho de que el tabaquismo tuviera un efecto en otros, especialmente personas indefensas o que no habían escogido fumar, lo que fundamentó su impacto. Los participantes hacían al respecto comentarios como los siguientes: "no me gustaría que mis hijos pasaran por esta situación porque yo fumo", "no tienen culpa por sufrir de los malos hábitos" o "me da tristeza que los niños sufran". Por otra parte, los padres de familia no se preocupaban únicamente por sus propios hijos ("porque estamos haciendo daño al hijo, al de enfrente, al de junto") y no solamente percibían el impacto de estas imágenes los padres de niños chicos ("pienso en mis nietos y mis hijos, están apenas teniendo niños").

Avisos referentes a enfermedades crónicas y daños a corto plazo. El aviso gráfico I3, que muestra una boca con dientes amarillos y que menciona la pérdida de los dientes y cáncer de boca debido al consumo de tabaco, fue considerado el más impactante por la mayoría de los participantes (figura 2e). No se pudo distinguir las reacciones a los avisos I3 e I6 en los fumadores que tenían más de 40 años de edad, aquellos con nivel educativo menor a la licenciatura, y los que fumaron seis o más cigarros al día. El I6 muestra un hombre que está tosiendo y se acompaña de un mensaje que señala que el fumar causa enfermedades discapacitantes. Los resultados de la prueba de Kruskall-Wallis indicaron que no había diferencias en el lugar en el rango asignado al aviso I3 en las diferentes subpoblaciones.

\section{Discusión}

En general, en cada una de las cinco categorías de los avisos sobre las consecuencias del consumo del tabaco, hubo uno o dos avisos que fueron evaluados como más impactantes por los y las participantes en el estudio. Las imágenes o pictogramas parecen tener impacto en los fumadores, aunque el texto también fue evaluado como importante por algunos de los participantes. Específicamente, las imágenes de la categoría referente al cáncer de pulmón (P0 - P5) que incluían textos como "Fumar causa cáncer del pulmón", "Fumar provoca cáncer mortal del pulmón" y "Los ciga- 
rros causan cáncer de pulmón" fueron seleccionadas como impactantes con bastante frecuencia, aunque estos mensajes de texto han sido utilizados durante muchos años en las cajetillas y en los anuncios del tabaco. Sin embargo, al combinar estos textos con imágenes, al parecer el efecto en los fumadores fue diferente. Este hallazgo es coherente con un estudio realizado en Canadá ${ }^{19}$ donde los fumadores entrevistados reportaron que textos que informaban de los daños a la salud como "Fumar es una causa principal del cáncer de pulmón" eran los más efectivos para dejar de fumar.

Otros estudios acerca de las reacciones a las leyendas en cajetillas de cigarros no muestran diferencias por género; ${ }^{19}$ sin embargo, en el presente estudio las mujeres consideraron como los más impactantes el aviso gráfico que muestra dos niños sanos $(\mathrm{C} 0)$ con el texto "El humo del cigarro que inhalan los no fumadores contiene amoníaco, monóxido de carbono, que pueden perjudicar a sus hijos" y el aviso que expone un feto muerto en un frasco con formol con la leyenda "Fumar causa abortos espontáneos". Llama la atención que los hombres no seleccionaron como impactantes o llamativos los avisos gráficos relacionados con la fertilidad o la impotencia sexual.

El presente estudio exploró el impacto de los avisos gráficos en términos de si hacían que los fumadores pensaran en dejar de fumar. En comparación, una investigación realizada en Australia justo después de salir al mercado cajetillas de cigarros con avisos gráficos encontró que los fumadores percibieron más los avisos nuevos al sacar cigarrillos de la cajetilla y reportaron una mayor frecuencia de dejar de fumar el cigarrillo al notar el mensaje. El estudio concluyó que los nuevos avisos escritos hicieron que los fumadores pensaran más en el efecto dañino del tabaco y como consecuencia cambiaron sus acciones y fumaron menos, lo cual pudiera ser un primer paso hacia la cesación. ${ }^{20}$

Este estudio en fumadores mexicanos encontró que los avisos gráficos hacían que los fumadores pensaran en el impacto que tendría el consumo del tabaco en sus órganos, el dolor que pudiera provocar y el efecto que el humo del cigarro tendría en otras personas, especialmente los niños. Una investigación realizada en Canadá examinó el impacto de los avisos gráficos que se implementaron en ese país en relación con el hábito de los adultos al tabaco y encontró que los fumadores conocían bien los avisos y que pensaban y reflexionaban en torno a ello. Aun más importante fue que los fumadores que más leían, pensaban y discutían los avisos en la medición basal eran significativamente más propensos a dejar de fumar, intentarlo o, al menos, reducir la cantidad que fumaban durante los próximos seis meses. ${ }^{5}$ Por otra parte, otro estudio canadiense, de los mismos autores, indagó sobre la posibilidad de que los avisos que incluyen gráficos extremadamente impactantes o grotescos pudieran ser tan negativos que tuvieran diversos efectos no deseados. Tales impactos negativos potenciales eran: a) causar perturbación emocional; b) que los fumadores evitaran los avisos; c) que fuera a socavar la credibilidad del mensaje; y d) especialmente, que causara una reacción que implicara un aumento en el consumo del tabaco. Aunque ciertamente $36 \%$ de los entrevistados intentaron evitar los avisos, sólo 13\% sintieron que les faltaba credibilidad. Además, 19\% de los fumadores reportaron que los avisos gráficos les motivaron a fumar menos y $63 \%$ informó algún beneficio relacionado con la cesación. Sobre todo, para los fumadores que reportaron más miedo y asco en relación con las imágenes, era significativamente más probable que hubieran dejado de fumar, intentado dejar de fumar o reducido su nivel de consumo de tabaco. ${ }^{21}$

De manera similar a estos estudios canadienses, una investigación sobre los avisos utilizados actualmente en la Unión Europea evaluó su impacto en los fumadores; $14 \%$ dijeron que estaban menos dispuestos a fumar un cigarrillo al ver los avisos; $17.9 \%$ reportaron que los avisos los hicieron sentir más motivados a dejar de fumar; y 10.3\% dijeron que fumaban menos debido a los nuevos mensajes. Hubo una fuerte relación dosis-respuesta entre la intención de dejar de fumar y el impacto de los avisos; es decir, entre mayor era la intención de dejar de fumar mayor era el impacto de éstos. Por lo tanto, sus efectos se sintieron primordialmente entre los fumadores que ya estaban pensando en dejar de fumar. ${ }^{22}$

Los resultados de este estudio se encuentran limitados. En concreto, debido al tamaño de muestra, muchos de los análisis estratificados no logran ser concluyentes, por lo que se sugiere llevar a cabo investigaciones con un mayor tamaño de la muestra, así como complementar este hallazgo con un estudio cualitativo de grupos focales. El uso de la técnica de sorteo de montones permitió explorar las reacciones a un número relativamente grande de imágenes, lo cual no hubiera sido posible en grupos focales. Por la misma profundidad que ofrece la metodología de los grupos focales, sería imposible incluir múltiples imágenes.

Es importante mencionar que esta investigación simplemente evalúa la reacción ante un aviso gráfico con su leyenda (en cuanto a si provoca el deseo de dejar de fumar), y no el impacto en el abandono del hábito de fumar, lo que sería ideal evaluar. Sin embargo, un estudio del impacto de los avisos gráficos no puede realizarse de manera directa antes de que éstos salgan al mercado en las cajetillas. En este contexto, el método de sorteo de montones aquí utilizado puede ser una manera alternativa rápida y fácil de implemen- 
tar en varios contextos que permita seleccionar las imágenes y los textos con mayor impacto, para posteriormente explorar a mayor profundidad la reacción de los fumadores a tales imágenes impactantes con estudios de tipo cualitativo como grupos focales y experimentos psicológicos. A través de la combinación de estas metodologías, una de las cuales permite abarcar un mayor número de imágenes (sorteo de montones) y otras que ofrecen una mayor profundidad (grupos focales) o datos estadísticamente significativos (encuestas, experimentos psicológicos o técnicas tomadas de la economía experimental), se podrá lograr entender las características del aviso gráfico y de los textos con mayor posibilidad de efecto disuasorio en los diferentes grupos de fumadores.

La implementación de etiquetas en las cajetillas de cigarros podría ayudar a alcanzar uno de los principios básicos del Convenio Marco para el Control del Tabaco (CMCT), ${ }^{9}$ el cual refiere que "todos deben estar informados de las consecuencias sanitarias, la naturaleza adictiva y la amenaza mortal del consumo del tabaco y de la exposición al humo de tabaco." La aplicación de una política de control al respecto podría además obligar a la industria tabacalera a pagar los costos de impresión que aparecen en las cajetillas, lo que hace que esta estrategia de comunicación sea más costo-efectiva que los anuncios en contra del tabaco transmitidos en los medios masivos de comunicación.

\section{Agradecimientos}

Este estudio fue posible gracias al financiamiento recibido de FOGARTY: R01-HL-73699.

\section{Referencias}

I. Ezzati M, Lopez AD. Regional disease specific patterns of smokingattributable mortality in 2000. Tob Control 2004;13:388-95.

2. Doll R, Peto R, Boreman J, Sutherland I. Mortality in relation to smoking: 50 years' observations on male British doctors. Br J Cancer 2005;92:426-9

3. US Department of Health and Human Services. The health consequences of smoking:A Report of the Surgeon General. Atlanta
(GA): USDHHS, Centers for Disease Control and Prevention. National Center for Chronic Disease Prevention and Health Promotion, Office on Smoking and Health, 2004.

4. US Department of Health and Human Services. Reducing the health consequences of smoking: 25 years of progress. A report of the Surgeon General. Bethesda, MD: USDHHS, 1989.

5. Hammond D, Fong GT, MacDonald P, Cameron R, Brown K. Impact of graphic Canadian warning labels on adult smoking behavior. Tob Control 2003; | 2:39|-395

6. Méndez-Toss M. Convenios para el control del tabaquismo establecidos por la Secretaría de Salud. En: Primer informe sobre combate al tabaquismo. México ante el convenio Marco para el Control del Tabaco. Cuernavaca, México: Instituto Nacional de Salud Pública, 2005:184-195.

7. Institute of Medicine. Speaking of health: Assessing health communication strategies for diverse populations. Washington DC: National Academy of Sciences, IOM, 2002.

8. Strahan E, White KS, Fong GT, Fabrigar L, Zanna M, Cameron R. Enhancing the effectiveness of message labels on tobacco packaging: $A$ social psychological perspective. Tob Control 2002; I I:183-190.

9. World Health Organization. Framework Convention on Tobacco Control.World Health Asembly resolution 56. I. May 2I, 2003. Geneva, Switzerland:WHO, Tobacco Free Initiative, 2003.

10. Graphic Health Warnings: Health Canada, 2005.

II. Indústria do tabaco deve utilizar novas imagens nas embalagens de cigarro. Brasil: Ministério de Saúde, 2004.

12. Press conference by Commissioner David Byrne on tobacco and cigarette packs illustrations: European Comission on Public Health, 2004. 13. Bernard HR. Research methods in anthropology: Qualitative and quantitative approaches. Walnut Creek, CA:AltaMira, 1994.

14. Bernard HR. Social research methods: Qualitative and quantitative approaches. Thousand Oaks, CA: Sage, 2000.

15. Denzin NK, Lincoln YS, editors. The handbook of qualitative research. Thousand Oaks, CA: Sage, 2000.

16. Nyamongo IK. Assessing intracultural variability statistically using data on malaria perceptions in Gusii, Kenya. Field Methods 2002;14:148-160.

17. Boster J.The Successive Pile Sort. Cultural Anthropology Methods 1994;6(2): II-12.

18. Conover WJ. Practical nonparametric statistics. 3rd ed. Nueva York: Wiley, 1998.

19. Crane FG, MacLean VA, Honors BC.A consumer evaluation of health warning labels on cigarette packages in Canada. Health Marketing Quarterly 1996;13(3):47-57.

20. Borland R. Tobacco health warnings and smoking-related cognitions and behaviours. Addiction 1997;92(I I): | 427-I 435.

2I. Hammond D, Fong GT, McDonald PW, Brown S, Cameron R. Graphic Canadian cigarette warning labels and adverse outcomes: Evidence from Canadian smokers. Am J Public Health 2004;94(8): I 442- 1445.

22. Willemsen MC. The new EU cigarette health warnings benefit smokers who want to quit the habit: results from the Dutch continuous survey of smoking habits. Eur Public Health 2005; I5(4):389-392 
Anexo I.

Descripción de los avisos gráficos evaluados en el estudio en Cuernavaca, Morelos, México 2005.

$\begin{array}{cccc}\text { Categoría No. } & \text { Texto } & \text { Imagen } \\ \text { de imagen } & \end{array}$

$\begin{array}{llllll}\text { Cáncer de pulmón } & \text { PO } & \text { Fumar causa cáncer del pulmón } & \text { Pieza patológica en bloque de los pulmones con cáncer } & \text { UE }\end{array}$

PI Los cigarros causan cáncer de pulmón $\quad$ Tumor de bronquio fuente visto a través del broncoscopio CA

P2 $\quad$ Fumar provoca cáncer mortal del pulmón $\quad$ Piezas de patología de los pulmones con daños por cáncer UE

P3 Fumar causa cáncer de pulmón Paciente hombre inconsciente intubado en la unidad

de cuidados intensivos UE

P4 Fumar causa cáncer de pulmón Paciente mujer conciente intubada en la unidad

de cuidados intensivos

BZS

P5 Fumar provoca cáncer mortal de pulmón

Paciente hombre conciente intubado en la unidad

UE

Otros daños

mortales a largo

O0 Fumar causa cáncer de garganta

plazo

OI Esta necrosis fue causada por consumo de tabaco

de cuidados intensivos

UE

Paciente hombre conciente con traqueostomía en la

unidad de cuidados intensivos

BS

Fotografía de miembro inferior necrótico por presentar

enfermedad arterial trombótica $\quad$ BS

O2 Los cigarros causan embolias y la muerte... Pieza de patología de un cerebro con trombosis cerebral

CA cerebro humano con embolia

O3 Fumar puede ser causa de una muerte lenta Paciente hombre con cáncer de laringe que presenta y dolorosa una gran masa tumoral externa en el cuello

una gran masa UE

O4 Él fue victima del tabaco...

Fumar puede llevar a amputaciones

O5 Fumar acorta la vida

inferiores

O6 Fumar obstruye las arterias $y$ causa ataques al corazón y embolias

O7 Fumar causa ataques al corazón

O8 Fumar causa ataques al corazón y la muerte

Cadáver

Cirugía de corazón abierto para realizar un UE bypass coronario

Paciente en resucitación cardio-pulmonar en urgencias $\quad$ BS

Corazón con daño miocárdico resultado de un

taponamiento de las arterias coronarias

\begin{tabular}{|c|c|c|c|c|}
\hline & & & taponamiento de las arterias coronarias & CA \\
\hline \multirow[t]{6}{*}{$\begin{array}{l}\text { Componentes } \\
\text { del cigarro }\end{array}$} & $\overline{\mathrm{CO}}$ & $\begin{array}{l}\text { El humo del cigarro que inhalan los } \\
\text { no fumadores contiene amoníaco, monóxido } \\
\text { de carbono, que pueden perjudicar a sus hijos }\end{array}$ & Niños sanos & $\mathrm{CA}$ \\
\hline & $\overline{\mathrm{Cl}}$ & $\begin{array}{l}\text { El humo de tabaco contiene benceno, } \\
\text { formaldehído, y cianuro de hidrógeno }\end{array}$ & $\begin{array}{l}\text { Paciente hombre inconsciente intubado en la unidad } \\
\text { de cuidados intensivos }\end{array}$ & UE \\
\hline & $\overline{\mathrm{C} 2}$ & $\begin{array}{l}\text { El humo del cigarro contiene más de } \\
500 \text { químicos que causan cáncer }\end{array}$ & Cigarrillo prendido & $\mathrm{CA}$ \\
\hline & $\overline{\mathrm{C} 3}$ & $\begin{array}{l}\text { Donde hay humo del cigarro, hay cianuro... } \\
\text { El cigarro causa dolor de cabeza, náuseas } \\
\text { y debilidad en fumadores y no fumadores }\end{array}$ & Humo del cigarro & CA \\
\hline & $\overline{\mathrm{C} 4}$ & $\begin{array}{l}\text { El humo del cigarro contiene químicos tóxicos, } \\
\text { como cianuro, benceno y formaldehído }\end{array}$ & Colillas de cigarrillos & $\mathrm{CA}$ \\
\hline & $\overline{\mathrm{C} 5}$ & $\begin{array}{l}\text { Al fumar inhala arsénico y naftalina, también } \\
\text { usados contra ratas y cucarachas }\end{array}$ & Rata y cucaracha muertas & UE \\
\hline \multirow{10}{*}{$\begin{array}{l}\text { Enfermedades } \\
\text { crónicas y } \\
\text { a corto plazo }\end{array}$} & 10 & Los cigarros son sumamente adictivos & Cenicero con muchas colillas de cigarrillos & CA \\
\hline & $\pi$ & Fumar causa impotencia sexual & Cigarrillo doblado & BS \\
\hline & 12 & Fumar puede dañar el esperma y reduce la fertilidad & Fotografía tridimensional de los espermatozoides & UE \\
\hline & 13 & Fumar causa cáncer de boca y pérdida de los dientes & Fotografía de dientes con daños por el consumo de tabaco & BS \\
\hline & 14 & Quien fuma se queda sin aliento & Hombre con dificultad respiratoria & BS \\
\hline & 15 & Fumar causa impotencia sexual & Pareja en la cama & BS \\
\hline & 16 & $\begin{array}{l}\text { Fumar causa enfermedades discapacitantes... } \\
\text { y con frecuencia mortales tales como el enfisema }\end{array}$ & $\begin{array}{l}\text { Hombre con mascarilla de oxígeno, con tos y } \\
\text { problemas al respirar. }\end{array}$ & CA \\
\hline & 17 & $\begin{array}{l}\text { Fumar provoca mal aliento, caída de los dientes } \\
\text { y cáncer bucal }\end{array}$ & Mujer rechazando a su pareja que está fumando & BS \\
\hline & 8 & El consumo de tabaco causa impotencia sexual & Cigarrillo doblado & CA \\
\hline & 19 & El tabaco es muy adictivo; no empiece a fumar & Hombre encarcelado entre las barras de cigarrillos & UE \\
\hline
\end{tabular}

Continúa... 
Continuación

Impacto en niños $y$ el feto
M0 Fumar durante el embarazo perjudica al bebé

MI Fumar durante el embarazo perjudica la salud de su hijo

M2 Fumar durante el embarazo perjudica la salud de su hijo

M3 Fumar durante el embarazo reduce el crecimiento de los bebés. Los bebés más pequeños tienen más riesgo de enfermedades y muerte

M4 Fumar causa abortos espontáneos

M5 Los niños empiezan a fumar al ver fumar a los adultos

M6 Proteja a los niños: no les haga respirar el humo de tabaco

M7 Los niños que conviven con fumadores padecen más asma, neumonía, sinusitis y alergias

M8 Proteja a los niños: no les haga respirar humo de tabaco

M9 Fumar causa partos prematuros y bebés con bajo peso
Mujer embarazada fumando

BS

Ecografía de un bebé

Fotografía de un feto vivo

UE

Mujer embarazada fumando

$\mathrm{CA}$

otografía de un feto muerto en un frasco con formol

BS

Adulto fumando al lado de un niño

BS

Niño con mascarilla de oxígeno

UE

Niñas en automóvil respirando humo de tabaco

BS

Niño respirando humo de tabaco

UE

Recién nacido en la unidad de cuidados intensivos

BS

$\mathrm{CA}=$ Canadá; $\mathrm{BS}=$ Brasil; $\mathrm{UE}=$ Unión Europea 